\title{
NUMERICAL INVESTIGATION OF NON-UNIFORM HEAT TRANSFER ENHANCEMENT IN PARABOLIC TROUGH SOLAR COLLECTORS USING DUAL MODIFIED TWISTED-TAPE INSERTS
}

\author{
Farhad Afsharpanah ${ }^{1}$, Amirhossein Zabihi Sheshpoli ${ }^{1}$, Khashayar Pakzad ${ }^{1}$, Seyed Soheil Mousavi \\ Ajarostaghi $1, *$
}

\begin{abstract}
In this paper, a numerical investigation is presented on heat transfer augmenting by using various kinds of modified multiple twisted tape inserted in solar parabolic trough collectors. The pressurized water is considered as working fluid and Reynolds number varying from 10000 to 20000 . The received heat flux on the solar absorber was assumed non-uniform due to hemispheric insolation of sun. The obtained numerical results for the Nusselt number, friction factor and thermal performance are presented for each cases. Various types of twisted tape including single twisted tape, normal, perforated, center-cleared, square, and V-cut dual twisted tape are considered and analyzed. The numerical simulations are performed by a commercial CFD code, ANSYS FLUENT 18.2. The obtained results revealed that at $\mathrm{Re}=10000$ and 20000 , the average Nusselt numbers of case with dual v-cut twisted tapes are more than plaine tube by 19.58 and $17.44 \%$, respectively. Moreover, thermal performance of all cases with various twisted tapes is larger than 1 which means that utilizing twisted tape with various configurations leads to more thermal performance than plain tube. The thermal performances of case with dual square-cut twisted tapes (as the best case) for $\mathrm{Re}=10000$ and 20000 are more than plain tube by about 16 and $12 \%$ improvement, respectively. Furthermore, for the case with perforated dual twisted tape (as the case with lowest thermal performance), the thermal performances for $\mathrm{Re}=10000$ and 20000 are more than plain tube by about 9.2 and $7 \%$ improvement, respectively.
\end{abstract}

Keywords: Heat Transfer Enhancement, Parabolic Trough Collector, Twisted Tape, Numerical Simulation, Solar Collector

\section{INTRODUCTION}

An increase in the global population has led to an ever-increasing demand for energy in the world. Given the limited resources available for fossil fuels, the environmental damages, and climate changes caused by emissions from burning these fuels, the share of renewable energy in overall energy consumption is rising [1,2]. Renewable energy can be categorized as wind, geothermal, biomass, hydropower, and solar energies. In the meantime, solar energy usage is more common due to better availability than other renewable energy sources [3].

Solar energy can be used in several forms such as solar water heating, solar drying, solar desalination, solar air conditioning, photovoltaic and solar thermal power systems [4]. In solar thermal power plants, solar radiation is collected by one or two-axis sun tracking collectors such as dishes or parabolic trough collectors (PTCs). The collected radiation energy is then focused a solar receiver where solar radiation is converted to heat and transferred to a fluid medium that can be used to generate steam, directly or indirectly in cycles such as Rankine power plant for producing electricity $[5,6]$.

PTCs systems, as shown in Figure 1, use a parabolic shape collector which concentrates solar radiation on a long absorber tube which contains a working fluid [7]. Also, PTCs is used in solar thermal power plants which use high temperatures in heating. These collectors can be used in lower temperature applications of industrial process heating $[8,9]$. The fluid in PTCs can be air, carbon dioxide, liquid sodium, molten salts, thermal oil or pressurized water that each of them has some advantages and disadvantages. For instance, air does not have a temperature constraint and it can be used for high-temperature usage, but it does not have good thermal properties like pressurized water. For liquid salts, the temperature has to be high enough to prevent crystallization. From the available fluid mediums for PTCs, pressurized water has very good thermal properties because of high values in density and heat capacity, but in

This paper was recommended for publication in revised form by Regional Editor ZERRİN SERT

${ }^{1}$ Department of Mechanical Engineering, Babol Noshirvani University of Technology, Babol, Iran

E-mail address: f.afsharpanah@gmail.com, amir.h.zabihi@nit.ac.ir, amirzabihi2018@gmail.com,kh.pakzad@stu.nit.ac.ir, s.s.mousavi@stu.nit.ac.ir, soheilmousavi67@gmail.com*

Orcid id: 0000-0001-5325-2381; 0000-0002-5334-3168; 0000-0001-8657-0992; 0000-0003-3813-4947

Manuscript Received 04 June 2020, Accepted 14 September 2020 
order to keep liquid phase during the heating process, the pressure has to be high ( 80 bar) [10]. PTCs efficiency can be improved by enhancements in tracker [11], geometry [12], absorber coatings [13] and working fluid [14-20]. Also, to increase the thermal behavior of PTC, phase change material storage [21,22] could be used to save the energy in peak hours a day.

Generally, PTCs are a kind of heat exchanger in which heat transfer enhancement methods for conventional kinds of heat exchanger can be applied to these systems. Heat transfer enhancement methods are generally divided into two categories: (a) active methods which use external energy source and (b) passive methods that work independently from any external source. Passive methods are cheaper and simpler to use, that's why using these techniques are more common. Extended surfaces [23-25], porous mediums [26-29], fluid additives [30-34] and swirl flow devices [35-37] can be placed in this category.

Twisted tapes (TTs) are one of swirl flow devices that can improve heat transfer by mixing fluid flow, inducing swirl flow near the tube wall and making turbulence intensity higher in these regions. TTs are not expensive and the process of making them or placing them in a tube is easy so they are an economical way to improve heat transfer. Although normal TTs can enhance heat transfer, they have the penalty of increasing the pressure drop. To further improving heat transfer or making pressure drop lower, many modified TTs has been designed and introduced by researchers [38]. Short-length [39], perforated [37], center-cleared [40], alternative axis [41], broken [42] and serrated TTs [43] are some of these modified TTs available in recent works. Also, in addition to using different kinds of insert in a pipe to increase the heat transfer, some researchers utilized various types of heat transfer fluid channel in order to heat transfer augmentation [44-49].

Despite many studies conducted to analyze the effects of utilizing different types of turbulators in tubes under uniform heat flux circumstances [50-52], there is not much attention focused on tubes with non-uniform heat flux to the authors' knowledge. Since PTCs concentrates a high amount of solar radiation on a portion of tube wall area, heat flux on tube walls in PTCs are non-uniform. This kind of circumferential heat flux can cause thermal distortion and thermal stress on the receiver, but it cannot be avoided due to hemispherical radiation of the sun, on the other hand inducing swirl flow in a tube and mixing it can improve heat transfer between the tube and fluid flow.

In the present work, a numerical investigation is presented to study the heat transfer and turbulent fluid flow of pressured water fluid flow in a PTC equipped with various kinds of TTs including single and dual counter-swirling TTs. Since dual TTs had better thermal performance than the single TT, modifications such as making TTs perforated, v-cut, square-cut and center-cleared are only applied to dual TT insertions which utilizing various kinds of TTs and comparison between the obtained numerical results are the novelty of the present work. Such a comprehensive work in which these various kinds of TTs could be compared with each other has not been presented in the previous works. The results for the Nusselt number and friction factor, as well as the thermal performance, are compared and discussed for each case.

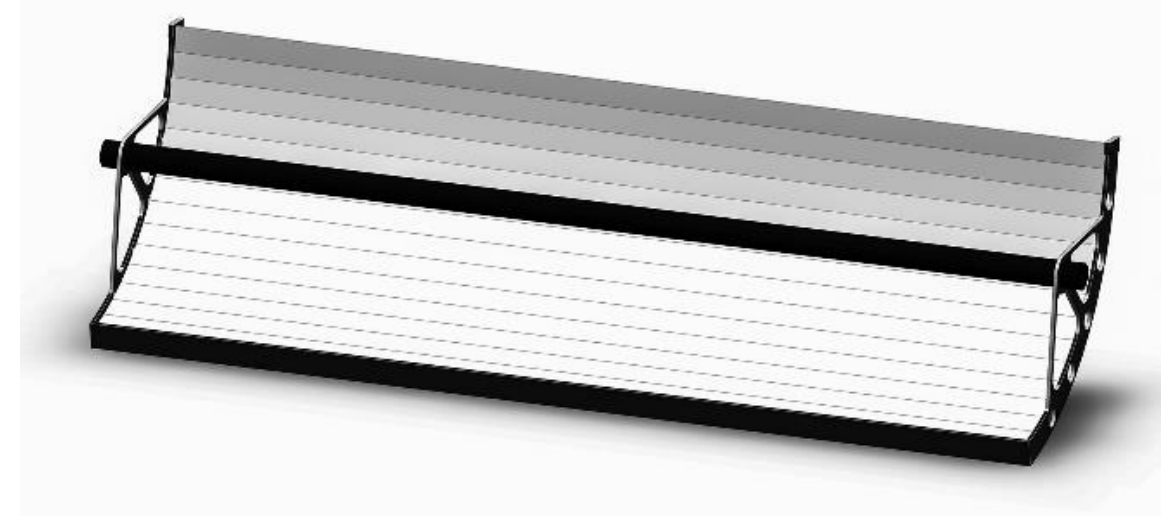


Figure 1. A unit of PTC structure.

\section{THEORY}

Governing equations are as follows:

Continuity:

$$
\frac{\partial\left(\rho u_{j}\right)}{\partial x_{j}}=0
$$

Momentum:

$$
\begin{gathered}
\frac{\left(\rho u_{i} u_{j}\right)}{\partial x_{i}}=\frac{\partial p}{\partial x_{i}}+\frac{\partial}{\partial x_{j}}\left\lfloor\mu\left(\frac{\partial u_{i}}{\partial x_{j}}+\frac{\partial u_{j}}{\partial x_{i}}\right)-\rho \overline{u_{\imath}^{\prime} u_{\jmath}^{\prime}}\right\rfloor \\
-\rho \overline{u_{\imath}^{\prime} u_{\jmath}^{\prime}}=\mu_{t}\left(\frac{\partial u_{i}}{\partial x_{j}}+\frac{\partial u_{j}}{\partial x_{i}}\right)-\frac{2}{3} k \delta_{i j}
\end{gathered}
$$

Energy:

$$
\frac{\partial}{\partial x_{i}}\left[u_{j(\rho E+p)}\right]=\frac{\partial}{\partial x_{j}}\left(k_{e f f} \frac{\partial T}{\partial x_{j}}\right)
$$

And for turbulence viscous model RNG K is used [53]:

$$
\begin{gathered}
\frac{\partial\left(p k u_{i}\right)}{\partial x_{i}}=\frac{\partial}{\partial x_{j}}\left(\alpha_{k} \mu_{e f f} \frac{\partial k}{\partial x_{j}}\right)+G_{k}-\rho \varepsilon \\
\frac{\partial\left(p \varepsilon u_{i}\right)}{\partial x_{i}}=\frac{\partial}{\partial x_{j}}\left(\alpha_{k} \mu_{e f f} \frac{\partial \varepsilon}{\partial x_{j}}\right)+\frac{C_{1 \varepsilon}}{k} G_{k}-C_{2 \varepsilon} \rho \frac{\varepsilon^{2}}{k}
\end{gathered}
$$

where $\mathrm{k}$ is defined as turbulent kinetic energy, $\varepsilon$ as dissipation rate, and $\mu_{\mathrm{ff}}$ and $\mathrm{G}_{\mathrm{k}}$ are the effective viscosity and generation of turbulent kinetic energy respectively. The effective viscosity is defined as follows:

$$
\mu_{e f f}=\mu+\mu_{t}=\mu+\rho C_{\mu} k^{2} / \varepsilon
$$

The model constants are $\alpha_{\varepsilon}=\alpha_{k}=1.393, \mathrm{C}_{1 \varepsilon}=1.42, \mathrm{C}_{2 \varepsilon}=1.68$, and $\mathrm{C}_{\mu}=0.0845$. The total rate of heat transfer is calculated using:

$$
Q=m c_{p}\left(T_{0}-T_{i}\right)
$$

and the average coefficient of convective heat transfer is obtained from:

$$
h=Q /\left[A\left(T_{w}-T_{b}\right)\right]
$$

In which $T_{w}$ is the wall average temperature and $T_{b}$ is used for showing bulk temperature. The following equations are acquired for determining: 
Reynolds Number:

$$
R e=d u \rho / \mu
$$

The friction factor:

$$
f=2 d \Delta p /\left(L \rho u^{2}\right)
$$

And the Nusselt Number:

$$
N u=h d / \lambda
$$

Finally, thermal performance is calculated using [54-59]:

$$
\eta=\frac{N u}{N u_{0}} /\left(\frac{f}{f_{0}}\right)^{\frac{1}{3}}
$$

The thermal performance can be used to analyze the overall thermal enhancement considering changes in heat transfer and the friction factor altogether.

\section{RESULTS AND DISCUSSION}

Figure 3 shows a transparent enclosure includes a particulate (participating) media. This figure describes the radiative phenomena inside a particulate media. When radiative energy travels through participating media, the incident beams are attenuated by scattering and absorption, while others are transmitted through this media to the other side.

\section{PHYSICAL MODEL}

Some various models of absorber tubes including plain tube and tubes equipped with single or dual normal or modified TTs have been investigated during this study. These modifications were performed on dual TTs: making them perforated, v-cut (V-C), square-cut (S-C), and center-cleared with two clearance width (C-C, w=2 and $3 \mathrm{~mm}$ ). Geometries are presented in Figure 2. Specifications for the Geometrical designs of the tube and tape are presented in Figure 3. Also, in Table 1 the values related to each of the structural parameters of geometries can be found.

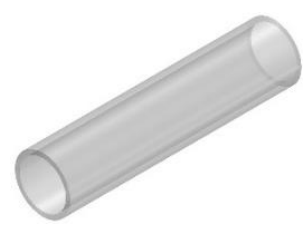

(a)

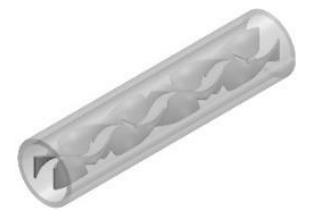

(e)

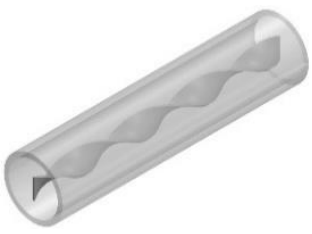

(b)

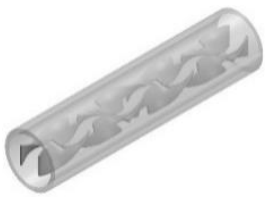

(f)

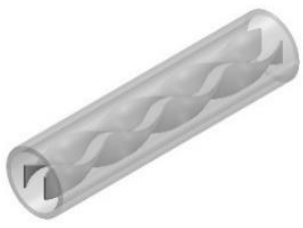

(c)

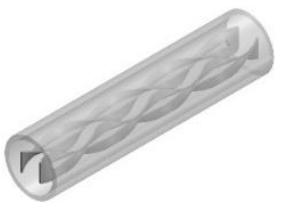

(g)

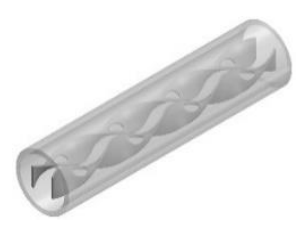

(d)

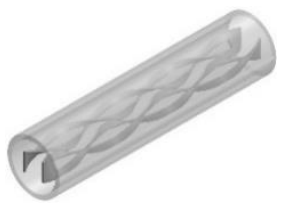

(h)

Figure 2. Absorber tubes structures. (a) Plain Tube, and the other tubes equipped with (b) Single TT, (c) Dual Normal, (d) Dual Perforated, (e) Dual V-C, (f) Dual S-C, (g) Dual C-C, w=2 mm, and (h) Dual C-C, 


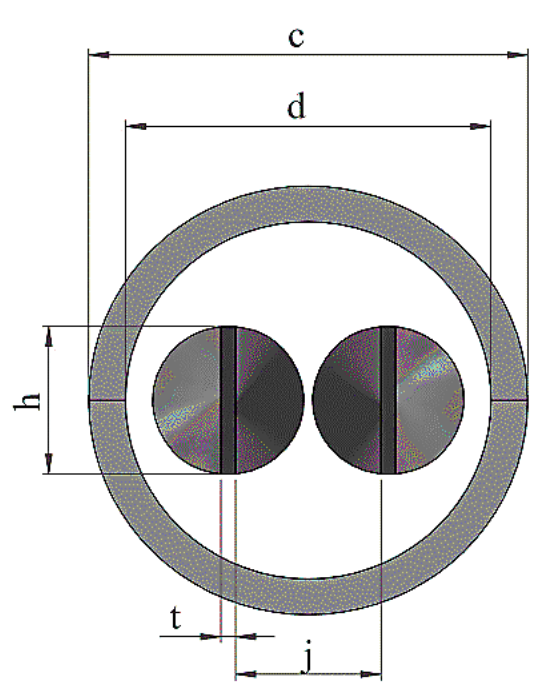

$\mathrm{W}=3 \mathrm{~mm}$.

Figure 3. Specifications for the geometrical design of the absorber tube and the TTs.

Table 1. Values Related to each of Geometrical Specifications of the Absorber Tube and The TTs in mm.

\begin{tabular}{|c|c|c|c|c|c|c|c|c|c|c|c|c|c|c|c|c|c|c|}
\hline $\mathbf{L}$ & $\mathbf{P}$ & $\mathbf{c}$ & $\mathbf{d}$ & $\mathbf{h}$ & $\mathbf{t}$ & $\mathbf{j}$ & $\mathbf{x}$ & $\mathbf{e}$ & $\mathbf{f}$ & $\mathbf{i}$ & $\mathbf{k}$ & $\mathbf{g}$ & $\mathbf{~}$ & $\mathbf{n}$ & $\mathbf{m}$ & $\mathbf{q}$ & $\mathbf{b}$ & $\mathbf{w}$ \\
\hline 100 & 25 & 24 & 20 & 8.25 & 0.8 & 7.95 & 10 & 5 & 25 & 12.5 & 1.75 & 25 & 3.5 & 10.75 & 3.5 & 12.5 & 5 & 2,3 \\
\hline
\end{tabular}

\section{SOLUTION SIMPLIFICATION AND BOUNDARY CONDITIONS}

First of all, the solution has been assumed at steady state. Fluid flow is turbulent and the Reynolds number varies from 10000 to 20000 . The working fluid is pressurized water and the hydraulic and thermal properties can be found in Table 2, as well as properties for Nickel-Chromium based alloy, alloy 625 which the absorber tube is selected to be made of.

Table 2. Thermal Properties for the working fluid and the tube.

\begin{tabular}{|c|c|c|c|}
\hline \multirow{2}{*}{ Property } & & \multicolumn{2}{|c|}{ Material } \\
\hline & & Pressurized Water & Alloy 625 \\
\hline \multirow{4}{*}{$\begin{array}{l}\text { Thermal Conductivity }\left[\mathrm{W} . \mathrm{m}^{-1} \cdot \mathrm{K}^{-1}\right] \\
\text { Density }\left[\mathrm{kg} . \mathrm{m}^{-3}\right] \\
\text { Specific Heat Capacity }\left[\mathrm{J} . \mathrm{kg}^{-1} \cdot \mathrm{K}^{-1}\right] \\
\text { Viscosity [Pa. sec] }\end{array}$} & $\lambda$ & 0.628 & 16.3 \\
\hline & $\rho$ & 994 & 8440 \\
\hline & $\mathbf{C P}_{\mathbf{P}}$ & 4164 & 505 \\
\hline & $\mu$ & $5.910^{-4}$ & - \\
\hline
\end{tabular}

The following assumptions have been used for simplifying:

- The outer wall of the absorber is assumed thermally insulated at the areas which it does not receive heat flux.

- Natural convection effects in heat transfer are neglected.

- Thermal properties of pressurized water as working fluid and alloy 625 material as the tube are considered constant.

The governing equations are solved by the commercial CFD code, ANSYS FLUENT 18.2 based on finite volume method (FVM). The discretization of the mass, momentum, and energy conservation equations are done by second-order upwind scheme. The velocity-pressure coupling is overcome by SIMPLE algorithm. The Green-Gauss cell-based method is used to calculate all gradients. The convergence criterion was fixed to $10^{-6}$ for residuals of the continuity, momentum, turbulence factors ( $\mathrm{k}$ and $\varepsilon$ ), and energy. 
The fluid temperature at the inlet is assumed to be $300 \mathrm{~K}$. The tube and TT walls have No-slip boundary condition. Also, a non-uniform heat flux is applied to the absorber wall, the heat flux distribution on the absorber tube is shown in Figure 4. It should be noted that $q^{\prime \prime}$ is assumed to be $600 \mathrm{kWs}$.

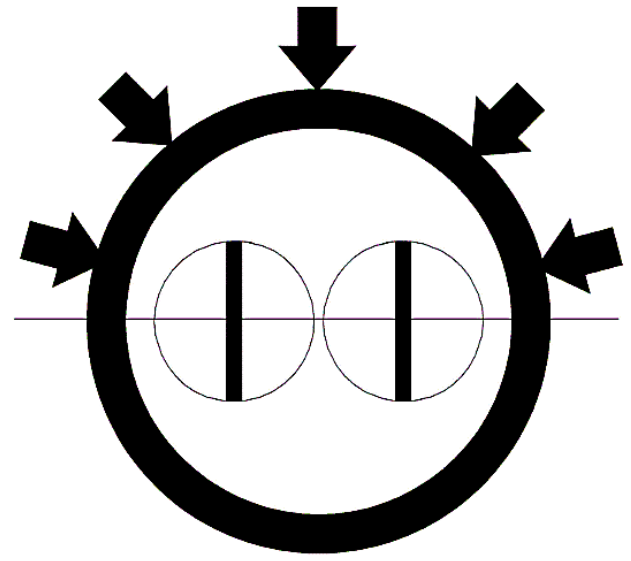

(a)

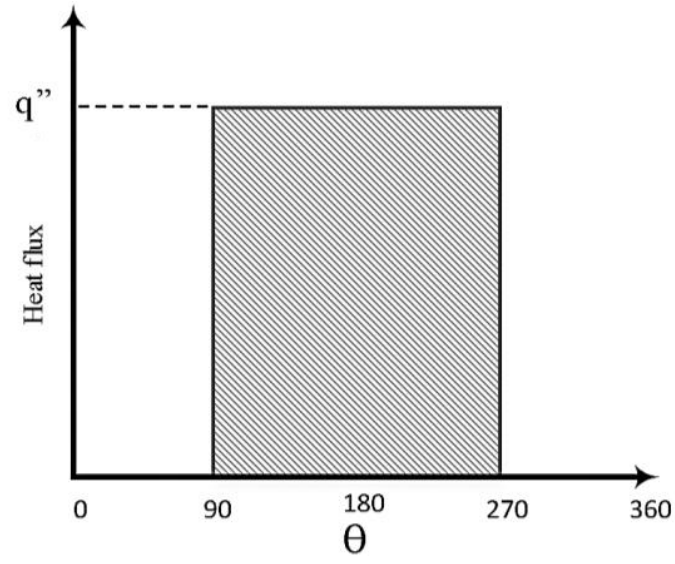

(b)

Figure 4. Non-Uniform heat flux distribution on absorber outer wall (a) schematic of the applied heat flux on the outer surface of the PTC, and (b) the range of te angular position under the heat flux.

\section{Grid Independency Analysis}

In mesh generations, it was preferred to use quad grids where possible, thus the tube itself and the delicate areas inside flow domain were covered with quad grids. The boundary layer meshes around TTs and tubes inner walls were used for enhancing mesh near the walls which higher temperature and velocity gradients. For the rest of the flow domain, curvature grids were used. The generated grid can be seen in Figure 5.

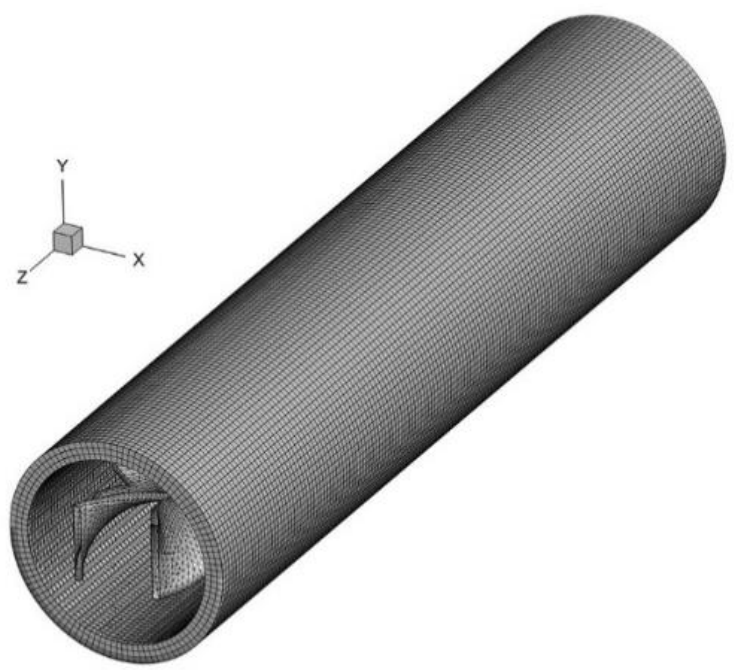

(a)

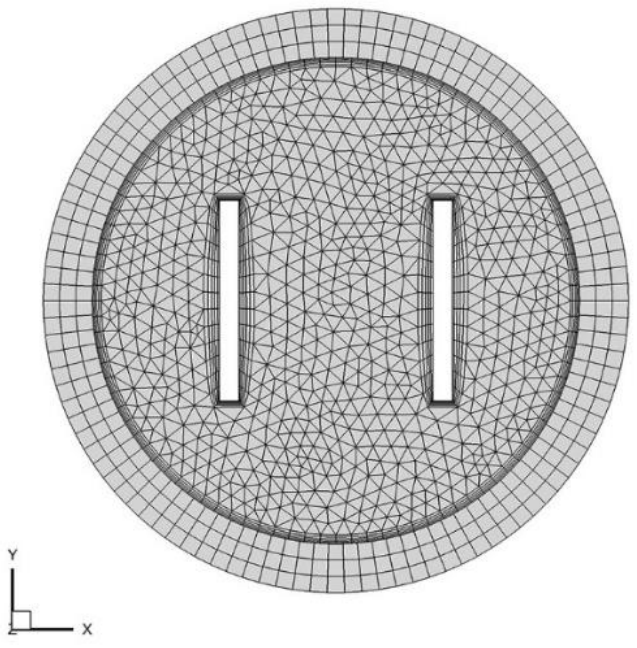

(b)

Figure 5. The generated grid for solar absorber in presence of dual TT (a) 3D, and (b) 2D pictures.

Tests for grid independence were performed for various element numbers of 720000, 860000, 1000,000 and 1150000 , the results for the Nusselt number were calculated and tabulated in Table 3. By comparison, it can be concluded that after reaching 1000000 number of grid elements, deviations of the Nusselt number becomes insignificant (smaller than $0.06 \%$ ), thus 1000000 grid number can be selected for further investigations during this study. 
Journal of Thermal Engineering, Research Article, Vol. 7, No. 1, pp. 133-147, January, 2021

Table 3. Results of grid independence tests

\begin{tabular}{|c|c|c|}
\hline Number of Grid Elements & Nu & Deviation in Nu (from selected one) (\%) \\
\hline 720000 cells & 384.318 & -3.02 \\
\hline 860000 cells & 392.679 & -0.91 \\
\hline 1000000 cells & 396.286 & - \\
\hline 1150000 cells & 396.524 & 0.06 \\
\hline
\end{tabular}

\section{Validation of Present Numerical Method}

For checking simulation validity, two cases are considered here. In the first one, results for the Nusselt number and friction factor for a plain tube in Reynolds number varying from 10000 to 20000 were calculated and compared with Gnielinski and Petukhov correlations [60]. The results have been plotted in Figure 6. It should be noted since Gnielinski correlation cannot be used for non-uniform heat flux circumstances, temporarily for validity checking only, the heat flux was assumed to be uniform. The maximum errors for Nusselt number and friction factor were found to be $4.09 \%$ and $2.29 \%$ respectively thus it can be said that the results are in acceptable agreement with other studies.

In the second case for validation, experimental results of Eiamsa-Ard et al. [61] for counter/co-swirling flow in a tube fitted with twin twisted tapes are used. The comparison analysis between the obtained numerical results and experimental results [61] is shown in Figure 7. Accordingly, it can be seen that in the second case, the maximum error between numerical and experimental results is about below $8 \%$ which shows that the presented numerical method is accurate.

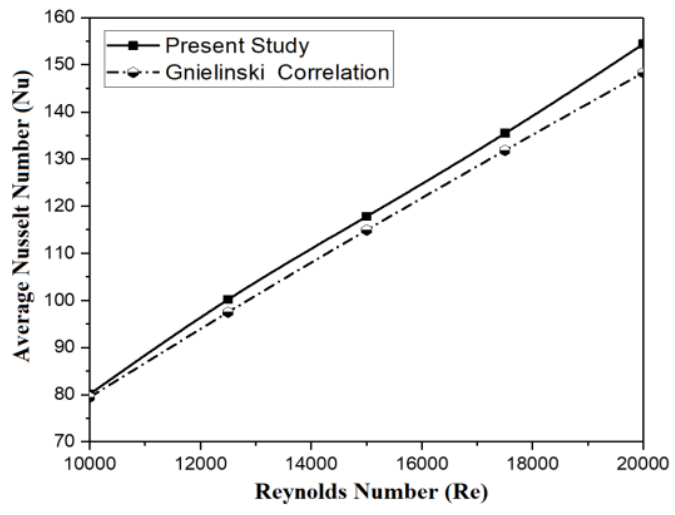

(a)

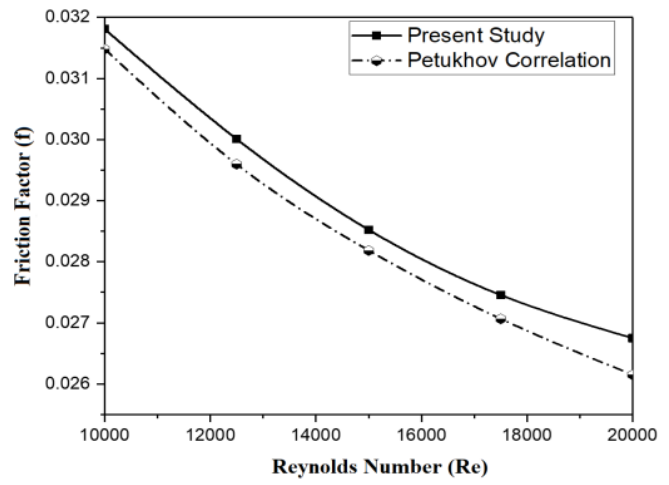

(b)

Figure 6. Checking simulation validity with Gnielinski and Petukhov correlations [60] (a) average Nusselt number and, (b) friction factor for a plain tube without TT.

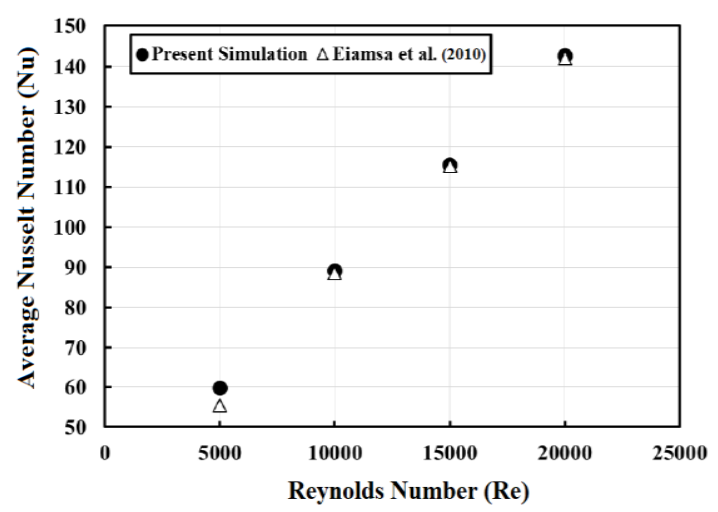

(a)

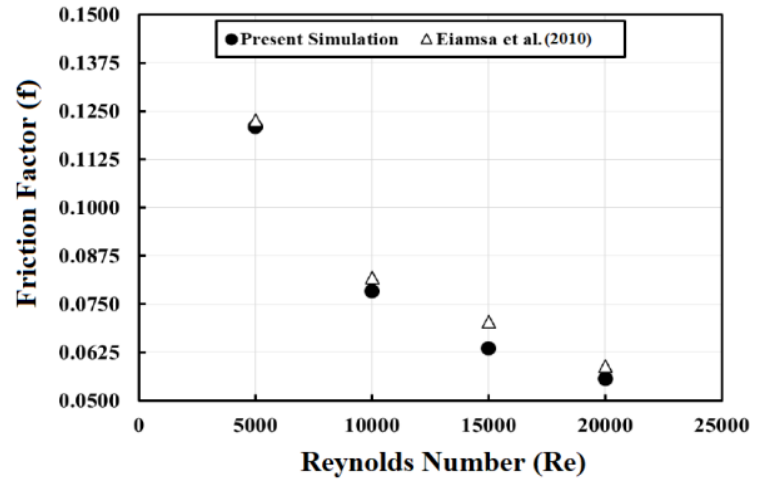

(b)

Figure 7. Validation of present numerical results with experimental results of Eiamsa-Ard et al. [61] (a) average Nusselt number, and (b) friction factor for counter/co-swirling flow in a tube fitted with twin twisted tapes. 
In the following sections section, hydraulic and thermal impacts of implementing various kinds of modified TTs will be discussed. First, we illustrate changes in flow pattern then we examine impacts of these changes in flow pattern on the Nusselt number, friction factor, and thermal performance.

\section{Impact of Utilizing Normal and Modified TTs on Flow Pattern}

Without TT insertion flow in the plain tube has an almost straight path, some fluctuation due to turbulence especially in higher Reynolds number is observed, but the overall path can be assumed straight. TT insertions completely change the flow pattern, at least in areas around TTs. Figure 8 presents velocity streamlines in case of using each of the TT insertions. According to Figure 8, in the cases with single or dual Normal TTs usage in the tubes, swirl flow and vorticities are created in areas around TTs. In other words, fluid flow near TTs has to follow the TT pattern in rotations and twists.

In cases with perforation, square-cuts, and center-clearance, though, due to created space for flow to pass, fluid flow has a straight way through TTs rather than swirling around them. Since the created space in case of using C-C with higher clearance width is larger for fluid flow to pass, swirl flow is more weakened in $\mathrm{C}-\mathrm{C}, \mathrm{w}=3 \mathrm{~mm}$ compared to $\mathrm{C}-\mathrm{C}, \mathrm{w}=2 \mathrm{~mm}$. V-Cuts, on the other hand, induces additional secondary flows around the cut helping better mixing and reducing boundary layer thickness because flow encountering with sharp edges of the cut. This is the main idea behind using V-Cut TTs.

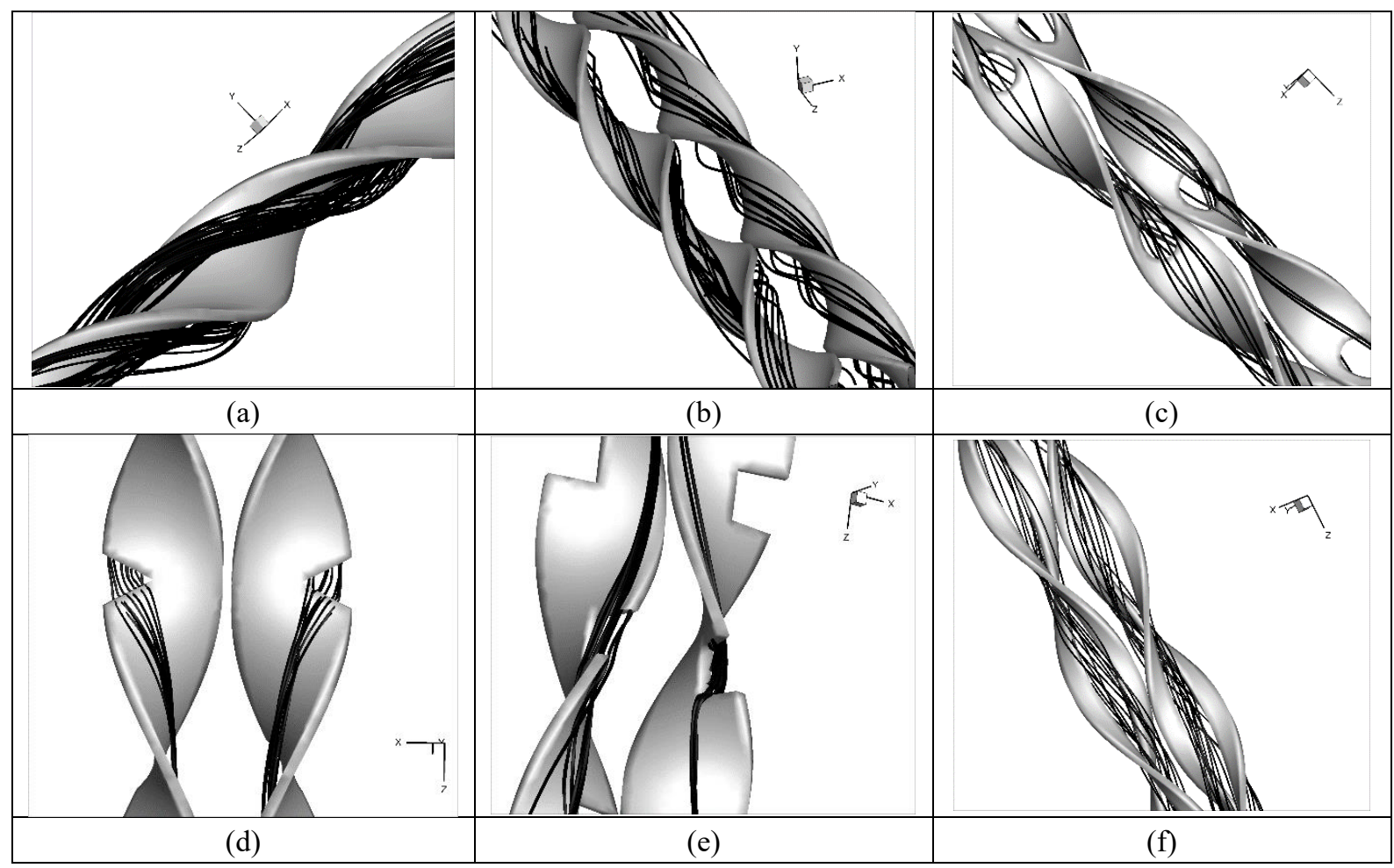

Figure 8. Velocity streamlines for absorbers with (a) Single TT, or dual (b) normal and modified TTs including (c) perforated, (d) V-C, (e) S-C and (f) C-C in the 15'000 Reynolds number.

\section{Impact of utilizing Normal and Modified TTs on Average Nusselt Number}

The main reason for utilizing TTs insertions is to improve the heat transfer. In present section, the influence of using various kinds of TTs on the heat transfer and average Nusselt number is investigated numerically. Figures 9a and $9 \mathrm{~b}$ present the average Nusselt number $(\mathrm{Nu})$ and average Nusselt number ratio $\left(\mathrm{Nu} / \mathrm{Nu}_{0}\right)$ versus different Reynolds numbers (Re) for all the cases, respectively. It should be noted that index 0 in refers to the case without TT (plain tube). 
As shown in Figure 9(a), it can be concluded that at larger Reynolds numbers, the average Nusselt number increases because of the force convection, whether there is a TT or not (plaine tube). This is due to higher turbulence in fluid flow for larger Reynolds number. The maximum average Nusselt number belongs to case with V-C TT in all five studied Reynolds number. For instance, it can be seen that at $\mathrm{Re}=10000$ and 20000, the average Nusselt numbers of case with dual V-C TT are more than plaine tube (without TT) by 19.58 and $17.44 \%$, respectively.

Also, Figure 9b shows that by increasing the Reynolds number, the ratio of average Nusselt number $\left(\mathrm{Nu} / \mathrm{Nu}_{0}\right)$ declines. In other words, the thermal effect of the presence of TTs in all of the examined cases fade and degrade in high Reynolds numbers. It is worth mentioning that the ratio of average Nusselt number of all studied cases is higher than 1 which means that inserting TT with any kind of geometry leads to a positive effect on heat transfer augmentation. The results show that the maximum ratio of average Nusselt number belongs to case with dual V-C TT in all considered Reynolds number. For instance, it can be seen in Figure $9 \mathrm{~b}$ that at $\mathrm{Re}=10000$ and 20000, the ratio of average Nusselt number of case with dual V-C TT are more than the case with single TT by 3.9 and 3.1\%, respectively.

Comparing the Nusselt number for cases single or dual TTs shows further improvements with dual TTs. The reason, as discussed in section 4.1, is higher turbulence and swirl flow induced by dual TT. Cases with perforations including square-cuts, and center-clearance allow flow to pass through in a more straightforward way so swirl flow in these cases are not as much as normal TT. As shown in Figure 8, an insignificant reduction in the Nusselt number is presented compare to cases with normal TTs. Comparing the Nusselt numbers for cases with C-C TTs, as mentioned before, this reduction is higher with larger center clearance width. As a result, using V-Cut TT insertion in PTCs induces additional secondary flows near the cuts thus the average Nusselt number becomes enlarged.

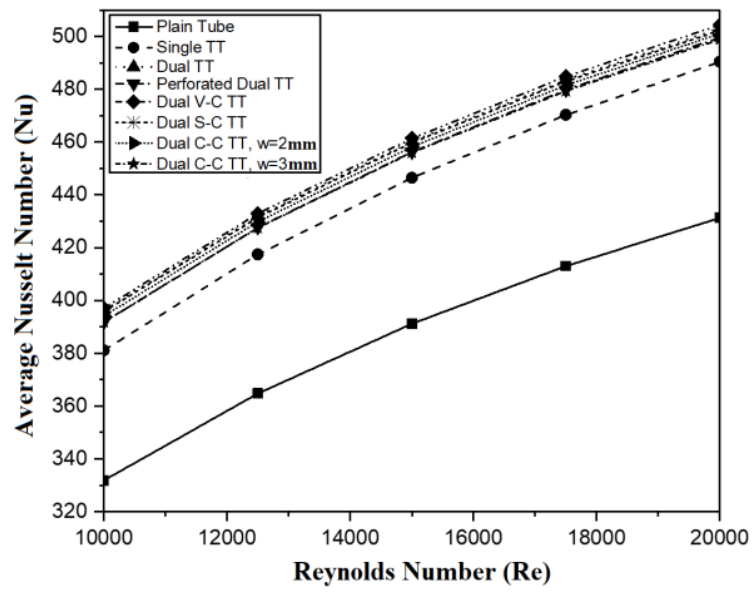

(a)

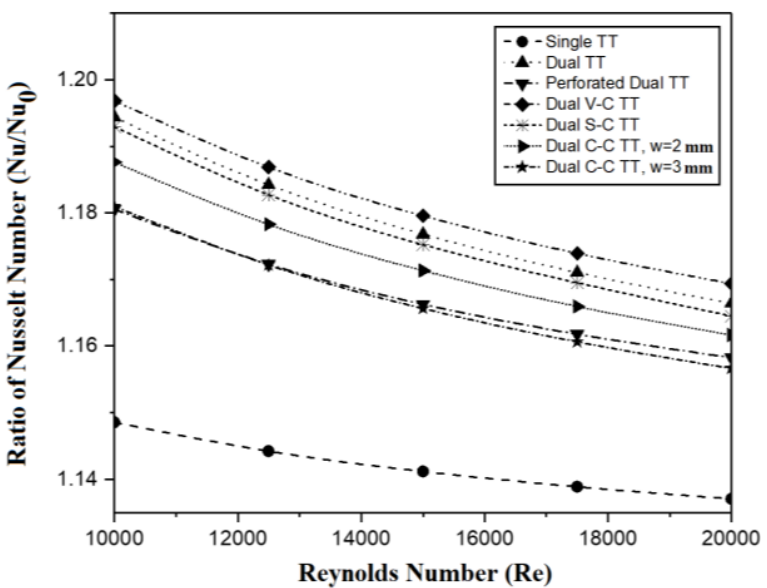

(b)

Figure 9. The Nusselt Number enhancements based on changes in TT configurations and Reynolds number, (a) average Nusselt number $(\mathrm{Nu})$ and (b) ration of average Nusselt number $\left(\mathrm{Nu} / \mathrm{Nu}_{0}\right)$.

( 0 is related to the plain tube.)

\section{Impact of Utilizing Normal and modified TTs on Friction Factor}

In this section, the effect of TTs configuration on friction factor in PTCs is studied and analyzed. Figures 10a and $10 \mathrm{~b}$ show the friction factor (f) and the ratio of friction factor $\left(\mathrm{f} / \mathrm{f}_{0}\right)$ versus different Reynolds number for different cases, respectively. It should be noted again that index 0 in refers to the case without TT (plain tube).

Generally, the friction factor for a turbulent flow in a tube is a function of relative roughness and Reynolds number. Here, the relative roughness of tube in all cases is kept constant. So, the friction factor changes just with the Reynolds number here. TT insertions increase friction factor due to flow blockage, larger flow path, the higher contact area with fluid flow and higher shear stress caused by additional turbulence created by TTs. Dual TTs, create these effects more so the friction factor for them will be larger compared to single TT implementations. 
Perforating dual TTs or making square-cut or center-cleared, decreases the contact region with fluid flow, it can also make flow path shorter by decreasing the share of swirl flow and altering some of it to non-swirling straight flow through the created space, thus it decreases the friction factor compared to normal dual TT inserts. V-cuts on the other hand, create additional secondary flows near cut regions, these extra vortexes as well as trapping the flow in the cut area, increases the friction factor.

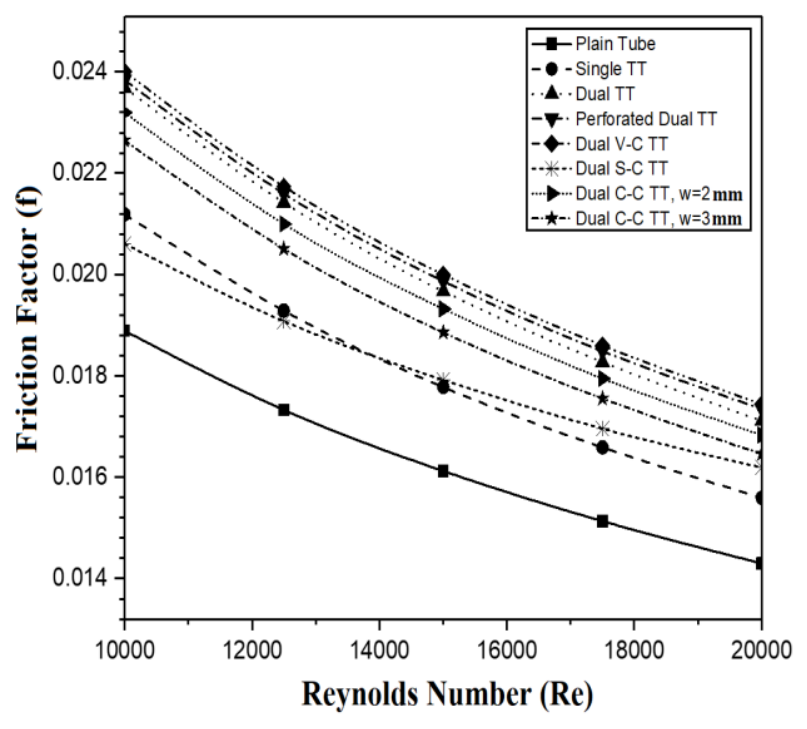

(a)

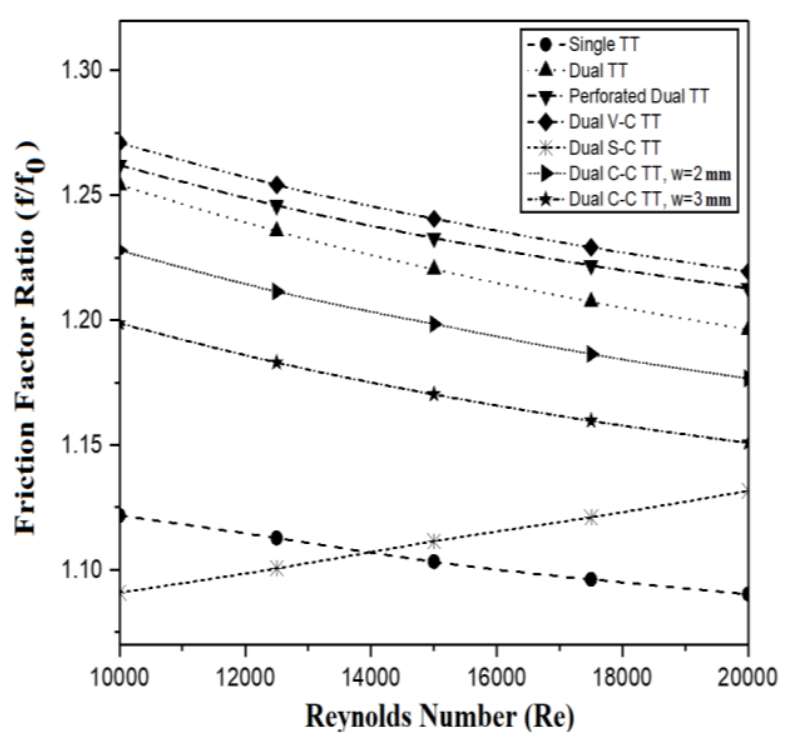

(b)

Figure 10. The friction factor alternations based on changes in TT configurations and Reynolds number, (a) friction factor $(f)$, and $(b)$ ratio of friction factor $\left(f / f_{0}\right)$. $(0$ is related to the plain tube.)

\section{Impact of Utilizing Normal and Modified TTs on Thermal Performance}

The thermal performance is calculated by using Equation 13 which shows that higher thermal performance leads to more heat transfer rate with lower pressure drop. On the other hand, thermal performance is an efficient parameter to analyze the effectiveness of utilizing a heat transfer enhancement method (like TTs). To evaluate if TTs insertion can overcome the penalty of enlarging friction factors in addition to more heat transfer rate, the thermal performance $(\eta)$ is introduced and calculated here to compare the obtained numerical results reasonably. Figure 11 presents the thermal performance versus different Reynolds number for all studied configurations of TTs insertion compared to the one without it (plain tube).

As shown in Figure 11, thermal performance for all the examined cases with TT insertion is larger than 1 which means that utilizing TT with any kinds of configuration leads to more thermal performance in comparison with plain tube. Also, the lowest thermal performance belongs to the case with perforated dual TTs because of larger friction factor ratio for this configurations, however, the thermal performance of this case is more than unity which shows better thermal performance than the plain tube without TT. In all the studied Reynolds numbers, tubes with dual S-C TTs shows highest thermal performance significantly. Moreover, thermal performance of this case degrades with larger Reynolds numbers, as the friction factor ratio rises. For instance, the thermal performances of case with dual S-C TT insert (as the best case) for $\mathrm{Re}=10000$ and 20000 (as lowest and highest studied Reynolds number) are more than plain tube (without TT) by about 16 and 12\% improvement, respectively. Furthermore, for the case with perforated dual TT (as the case with lowest thermal performance), the thermal performances for $\mathrm{Re}=10000$ and 20000 (as lowest and highest studied Reynolds number) are more than plain tube (without TT) by about 9.2 and $7 \%$ improvement, respectively 


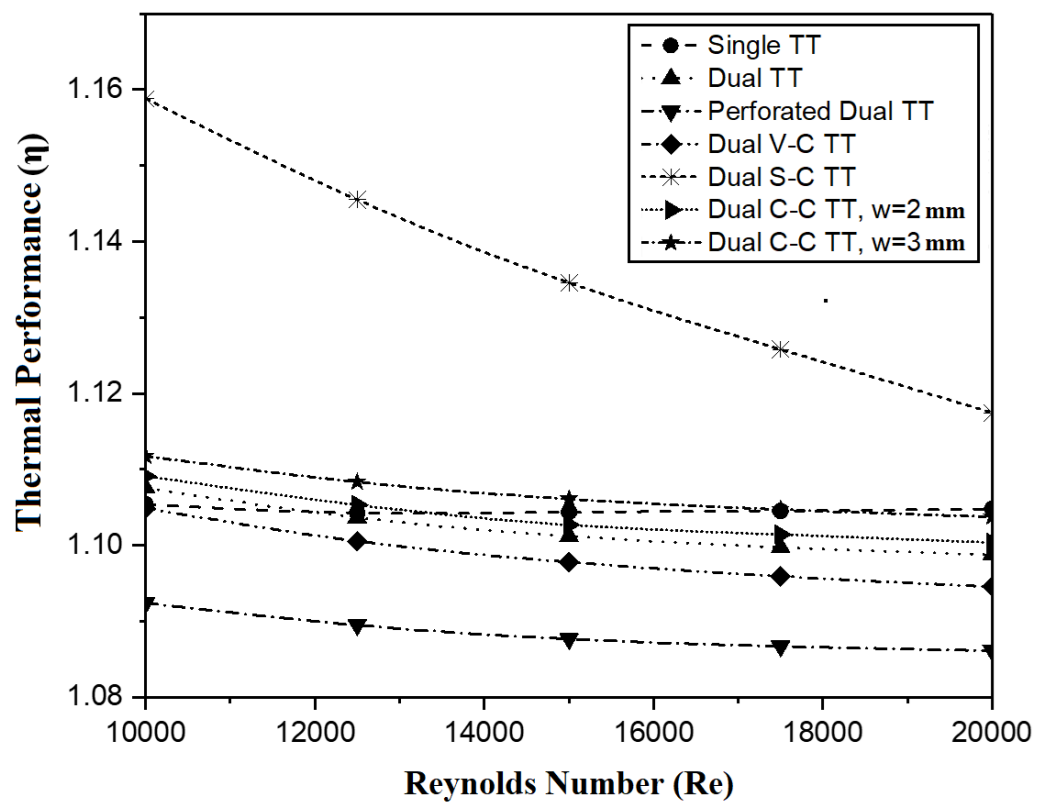

Figure 11. The thermal performance $(\eta)$ versus different Reynolds number based on changes in TT configurations, compared to plain tube absorber.

\section{CONCLUSION AND FUTURE SCOPE}

In this article, numerical method was used to investigate the impact of utilizing various types of twisted tape in the absorber of solar parabolic trough collector on heat transfer, friction factor and thermal performance. Modifications were applied to dual twisted tape inserts such as making perforated, v-cut, square-cut, and centercleared. The heat flux was assumed non-uniform due to special circumstances of parabolic trough collectors. The obtained results are as follows:

- At $\mathrm{Re}=10000$ and 20000, the average Nusselt numbers of case with dual v-cut twisted tapes are more than plaine tube by 19.58 and $17.44 \%$, respectively.

- The thermal performance of all cases with various twisted tapes is larger than 1 which means that utilizing twisted tape with various configurations leads to more thermal performance than plain tube.

- The thermal performances of case with dual square-cut twisted tapes (as the best case) for Re=10000 and 20000 are more than plain tube by about 16 and $12 \%$ improvement, respectively.

- For the case with perforated dual twisted tape (as the case with lowest thermal performance), the thermal performances for $\mathrm{Re}=10000$ and 20000 are more than plain tube by about 9.2 and $7 \%$ improvement, respectively.

It is worth mentioning that more numerical studies are necessary to extend the flow solver to model the complex turbulence flow in the proposed heat exchanger. Also, performing experimental tests are required to gained all results for improve the heat transfer in the proposed heat exchanger. Furthermore, different kinds of vortex generators (turbulators) could be utilized and evaluated experimentally and numerically.

FUNDING: This research received no external funding.

CONFLICTS OF INTEREST: The authors declare no conflict of interest.

\section{NOMENCLATURE}

$C_{p} \quad$ Specific heat capacity, $\mathrm{kJ} \cdot \mathrm{kg}^{-1} \cdot \mathrm{K}^{-1}$

$d \quad$ Tube inner diameter, $\mathrm{m}$ 


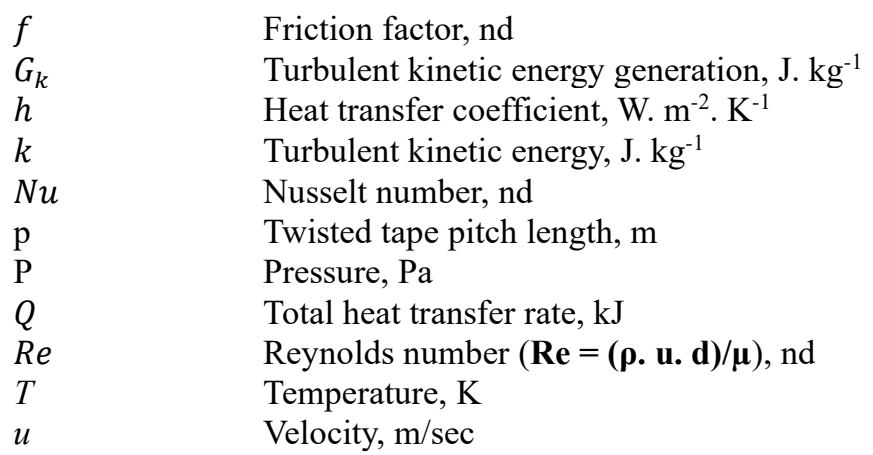

Greek symbols

$\eta$

$\lambda$

$\mu$

$\rho$

$\begin{array}{ll}\text { Subscripts } & \\ b & \text { Bulk } \\ \text { eff } & \text { Effective } \\ w & \text { Wall }\end{array}$

Abbreviation PTCs TTs
Turbulent kinetic energy dissipation rate, $\mathrm{J}_{\mathrm{kg}} \mathrm{kg}^{-1} \cdot \mathrm{ses}^{-1}$

Thermal performance, nd

Thermal conductivity, W. $\mathrm{m}^{-1} \cdot \mathrm{K}^{-1}$

Fluid viscosity, kg. $\mathrm{m}^{-1}$. $\mathrm{sec}^{-1}$

Density, kg. $\mathrm{m}^{-3}$

Parabolic Trough Collectors

Twisted Tapes

\section{REFERENCES}

[1] Gozgor G., CKM L. and Lu Z. Energy consumption and economic growth: New evidence from the OECD countries. Energy 2018;153;27-34. doi: 10.1016/j.energy.2018.03.158.

[2] Apergis N. and Payne J.E. Renewable and non-renewable energy consumption-growth nexus: Evidence from a panel error correction model. Energy Economics 2012;34(3);733-738. doi: 10.1016/j.eneco.2011.04.007.

[3] Tiwari, G.N. and R.K. Mishra, Advanced renewable energy sources. 2012: Royal Society of Chemistry.

[4] Duffie, J.A. and W.A. Beckman, Solar engineering of thermal processes. 2013: John Wiley \& Sons.

[5] Behar O., Khellaf A. and Mohammedi K. A review of studies on central receiver solar thermal power plants. Renewable and sustainable energy reviews 2013;23;12-39. doi: 10.1016/j.rser.2013.02.017.

[6] Changa C., Xu C., Wu Z.Y., Li X., Zhang Q.Q. and Wang Z.F. Heat transfer enhancement and performance of solar thermal absorber tubes with circumferentially non-uniform heat flux. Energy Procedia 2015;69;320-327. doi: 10.1016/j.egypro.2015.03.036.

[7] Chahine K., Murr R., Ramadan M., El Hage H. and Khaled M. Use of parabolic troughs in HVAC applications-Design calculations and analysis. Case Studies in Thermal Engineering 2018;12;285-291. doi: 10.1016/j.csite.2018.04.016.

[8] Akbarzadeh S. and Valipour M.S. Heat transfer enhancement in parabolic trough collectors: A comprehensive review. Renewable and Sustainable Energy Reviews 2018;92;198-218. doi: 10.1016/j.rser.2018.04.093.

[9] Habibi H., Zoghi M., Chitsaz A. and Shamsaiee M. Thermo-economic performance evaluation and multiobjective optimization of a screw expander-based cascade Rankine cycle integrated with parabolic trough solar collector. Applied Thermal Engineering 2020;115827. doi: 10.1016/j.applthermaleng.2020.115827.

[10] Bellos, E., Tzivanidis C. and Antonopoulos K.A. A detailed working fluid investigation for solar parabolic trough collectors. Applied Thermal Engineering 2017;114;374-386. doi: 10.1016/j.applthermaleng.2016.11.201.

[11] Sun J., Wang R., Hong H. and Liu Q. An optimized tracking strategy for small-scale double-axis parabolic 
Journal of Thermal Engineering, Research Article, Vol. 7, No. 1, pp. 133-147, January, 2021

trough collector. Applied Thermal Engineering 2017;112;1408-1420. doi: 10.1016/j.applthermaleng.2016.10.187.

[12] Thomas, A. and Guven, H. M. Parabolic trough concentrators-design, construction and evaluation. Energy Conversion and Management 1993;34(5);401-416. doi: 10.1016/0196-8904(93)90090-W.

[13] Kasaeian A., Daviran S. and Azarian R.D. Optical and thermal investigation of selective coatings for solar absorber tube. International Journal of Renewable Energy Research (IJRER) 2016;6(1);15-20.

[14] Mwesigye A. and Huan Z. Thermodynamic analysis and optimization of fully developed turbulent forced convection in a circular tube with water- $\mathrm{Al}_{2} \mathrm{O}_{3}$ nanofluid. International Journal of Heat and Mass Transfer 2015;89;694-706. doi: 10.1016/j.ijheatmasstransfer.2015.05.099.

[15] Hussein A.K. Applications of nanotechnology in renewable energies-A comprehensive overview and understanding. Renewable and Sustainable Energy Reviews 2015;42;460-476. doi: 10.1016/j.rser.2014.10.027.

[16] Hussein A.K., Walunj A. and Kolsi L. Applications of nanotechnology to enhance the performance of the direct absorption solar collectors. Journal of Thermal Engineering 2016;2(1);529-540. doi:10.18186/jte.46009.

[17] Hussein, A.K. Applications of nanotechnology to improve the performance of solar collectors - Recent advances and overview. Renewable and Sustainable Energy Reviews 2016;62;767-792. doi: 10.1016/j.rser.2016.04.050.

[18] Hussein A.K., Li D., Kolsi L., Kata S. and Sahoo B. A review of nano fluid role to improve the performance of the heat pipe solar collectors. Energy Procedia 2017;109;417-424. doi: 10.1016/j.egypro.2017.03.044.

[19] Ghiasi, E. K. and Saleh R. Thermophysical Investigation of Unsteady Casson-Carreau Fluid. INAE Letters 2019;4(4);227-239. doi: 10.1007/s41403-019-00082-w.

[20] Khoshrouye Ghiasi E. and Saleh R. A Series Solution for Melting Heat Transfer Characteristics of Hybrid Casson Fluid Under Thermal Radiation. Eng. Appl. Sci. Lett 2019;2(4);21-32. doi:10.30538/psrpeas12019.0028.

[21] Li D., Li Z., Zheng Y., Liu C., Hussein A.K. and Liu X. Thermal performance of a PCM-filled double-glazing unit with different thermophysical parameters of PCM. Solar Energy 2016;133;207-220. doi: 10.1016/j.solener.2016.03.039.

[22] Liu C., Wu Y., Li D., Ma T., Hussein A.K. and Zhou Y. Investigation of thermal and optical performance of a phase change material filled double-glazing unit. Journal of Building Physics 2018;42(2);99-119. doi: $10.1177 / 1744259117708734$.

[23] Noorbakhsh M., Zaboli M. and Ajarostaghi S.S.M. Numerical evaluation of the effect of using twisted tapes as turbulator with various geometries in both sides of a double-pipe heat exchanger. Journal of Thermal Analysis and Calorimetry 2020;140(3);1341-1353. doi: 10.1007/s10973-019-08509-w.

[24] Baou M., Afsharpanah F. and Delavar M.A. Numerical study of enhancing vehicle radiator performance using different porous fin configurations and materials. Heat Transfer-Asian Research 2020;49(1);502-518. doi: 10.1002/htj.21624.

[25] Gong X., Wang F., Wang H., Tan J., Lai Q. and Han H. Heat transfer enhancement analysis of tube receiver for parabolic trough solar collector with pin fin arrays inserting. Solar Energy 2017;144;185-202. doi: 10.1016/j.solener.2017.01.020.

[26] Heyhat M.M., Valizade M., Abdolahzade S. and Maerefat M. Thermal efficiency enhancement of direct absorption parabolic trough solar collector (DAPTSC) by using nanofluid and metal foam. Energy 2020;192; 116662. doi: 10.1016/j.energy.2019.116662.

[27] Baragh S., Shokouhmand H., Ajarostaghi S.S.M. and Nikian M. An experimental investigation on forced convection heat transfer of single-phase flow in a channel with different arrangements of porous media. International Journal of Thermal Sciences 2018;134;370-379. doi: 10.1016/j.ijthermalsci.2018.04.030.

[28] Baragh S., Shokouhmand H. and Ajarostaghi, S.S.M. Experiments on mist flow and heat transfer in a tube fitted with porous media. International Journal of Thermal Sciences 2019;137;388-398. doi: 10.1016/j.ijthermalsci.2018.11.030.

[29] Ajarostaghi S.S.M., Delavar M.A. and Poncet S. Thermal mixing, cooling and entropy generation in a micromixer with a porous zone by the lattice Boltzmann method. Journal of Thermal Analysis and Calorimetry 
Journal of Thermal Engineering, Research Article, Vol. 7, No. 1, pp. 133-147, January, 2021

2020;140(3);1321-1339. doi: 10.1007/s10973-019-08386-3.

[30] De los Rios M.S.B., Rivera-Solorio C.I. and García-Cuéllar A.J. Thermal performance of a parabolic trough linear collector using $\mathrm{Al}_{2} \mathrm{O}_{3} / \mathrm{H}_{2} \mathrm{O}$ nanofluids. Renewable Energy 2018;122;665-673. doi: 10.1016/j.renene.2018.01.094.

[31] Karouei S.H.H., Ajarostaghi S.S.M., Gorji-Bandpy, M. and Fard S.R.H. Laminar heat transfer and fluid flow of two various hybrid nanofluids in a helical double-pipe heat exchanger equipped with an innovative curved conical turbulator. Journal of Thermal Analysis and Calorimetry 2020;1-12. doi: 10.1007/s10973-020-09425-0.

[32] Hamedani F.A., Ajarostaghi S.S.M. and Hosseini S.A. Numerical evaluation of the effect of geometrical and operational parameters on thermal performance of nanofluid flow in convergent-divergent tube. Journal of Thermal Analysis and Calorimetry 2019;1-23. doi: 10.1007/s10973-019-08765-w.

[33] Zaboli M., Ajarostaghi S.S.M., Noorbakhsh M. and Delavar M.A. Effects of geometrical and operational parameters on heat transfer and fluid flow of three various water based nanofluids in a shell and coil tube heat exchanger. SN Applied Sciences 2019;1(11);1387. doi: 10.1007/s42452-019-1431-2.

[34] Ajarostaghi S.S.M., Zaboli M. and Nourbakhsh M. Numerical evaluation of turbulence heat transfer and fluid flow of hybrid nanofluids in a pipe with innovative vortex generator. Journal of Thermal Analysis and Calorimetry 2020;1-15. doi: 10.1007/s10973-020-10205-z.

[35] Outokesh M., Ajarostaghi S.S.M., Bozorgzadeh A. and Sedighi K. Numerical evaluation of the effect of utilizing twisted tape with curved profile as a turbulator on heat transfer enhancement in a pipe. Journal of Thermal Analysis and Calorimetry 2020;1-17. doi: 10.1007/s10973-020-09336-0.

[36] Moghadam H.K., Ajarostaghi S.S.M. and Poncet S. Extensive numerical analysis of the thermal performance of a corrugated tube with coiled wire. Journal of Thermal Analysis and Calorimetry 2019;1-13. doi: 10.1007/s10973-019-08876-4.

[37] Afsharpanah F., Pakzad K., Amirsoleymani M. and Delavar M.A. Numerical study of heat transfer enhancement using perforated dual twisted tape inserts in converging-diverging tubes. Heat Transfer-Asian Research 2018;47(5);754-767. doi: 10.1002/htj.21340.

[38] Saysroy A. and Eiamsa-ard S. Periodically fully-developed heat and fluid flow behaviors in a turbulent tube flow with square-cut twisted tape inserts. Applied Thermal Engineering 2017;112;895-910. doi: 10.1016/j.applthermaleng.2016.10.154.

[39] Eiamsa-Ard S., Thianpong C., Eiamsa-Ard P. and Promvonge P. Convective heat transfer in a circular tube with short-length twisted tape insert. International communications in heat and mass transfer 2009;36(4);365-371. doi: 10.1016/j.icheatmasstransfer.2009.01.006.

[40] Zaboli M., Nourbakhsh M. and Ajarostaghi S.S.M. Numerical evaluation of the heat transfer and luid low in a corrugated coil tube with lobe-shaped cross-section and two types of spiral twisted tape as swirl generator. Journal of Thermal Analysis and Calorimetry 2020. doi:10.1007/s10973-020-10219-7.

[41] Salman S.D., Kadhum A.A.H., Takriff M.S. and Mohamad A.B. CFD simulation of heat transfer augmentation in a circular tube fitted with alternative axis twisted tape in laminar flow under a constant heat flux. Heat Transfer-Asian Research 2014;43(4);384-396. doi: 10.1002/htj.21089.

[42] Chang S.W., Yang T.L. and Liou J.S. Heat transfer and pressure drop in tube with broken twisted tape insert. Experimental Thermal and Fluid Science 2007;32(2;489-501. doi: 10.1016/j.expthermflusci.2007.06.002.

[43] Eiamsa-Ard S. and Promvonge P. Thermal characteristics in round tube fitted with serrated twisted tape. Applied Thermal Engineering 2010;30(13);1673-1682. doi: 10.1016/j.applthermaleng.2010.03.026.

[44] Afsharpanah F., Ajarostaghi S.S.M. and Sedighi K. The influence of geometrical parameters on the ice formation enhancement in a shell and double coil ice storage system. SN Applied Sciences 2019;1(10);1264. doi: 10.1007/s42452-019-1317-3.

[45] Pakzad K., Ajarostaghi S.S.M. and Sedighi K. Numerical simulation of solidification process in an ice-on-coil ice storage system with serpentine tubes. SN Applied Sciences 2019;1(10);1258. doi: 10.1007/s42452-019$1316-4$.

[46] Ajarostaghi S.S.M., Poncet S., Sedighi K. and Delavar M.A. Numerical modeling of the melting process in a shell and coil tube ice storage system for air-conditioning application. Applied Sciences 2019;9(13);2726. doi: 
Journal of Thermal Engineering, Research Article, Vol. 7, No. 1, pp. 133-147, January, 2021

10.3390/app9132726.

[47] Ajarostaghi S.S.M., Sedighi K., Delavar M.A. and Poncet S. Numerical Study of a Horizontal and Vertical Shell and Tube Ice Storage Systems Considering Three Types of Tube. Applied Sciences 2020;10(3);1059. doi: 10.3390/app10031059.

[48] Javadi H., Ajarostaghi S.S.M., Pourfallah M. and Zaboli M. Performance analysis of helical ground heat exchangers with different configurations. Applied Thermal Engineering 2019;154;24-36. doi: 10.1016/j.applthermaleng.2019.03.021.

[49] Javadi H., Ajarostaghi S.S.M., Mousavi S.S. and Pourfallah M. Thermal analysis of a triple helix ground heat exchanger using numerical simulation and multiple linear regression. Geothermics 2019;81;53-73. doi: 10.1016/j.geothermics.2019.04.005.

[50] Tokgoz N., Alıç E., Kaşka Ö. and Aksoy M.M. The numerical study of heat transfer enhancement using $\mathrm{Al}_{2} \mathrm{O}_{3}$ water nanofluid in corrugated duct application. Journal of Thermal Engineering 2018;4(3);1984-1997. doi:10.18186/journal-of-thermal-engineering.409655.

[51] Sharma B. Effect of flow structure on heat transfer in compact heat exchanger by using finite thickness winglet at acute angle. Journal of Thermal Engineering 2017;3(2);1149-1162. doi: 10.18186/thermal.298616.

[52] Keklikcioglu O., Dagdevir T. and Ozceyhan V. A CFD Based Thermo-Hydroulic Performance Analysis in a Tube Fitted with Stepped Conical Nozzle Turbulators. Journal of Thermal Engineering 2016;2;913-920. doi: 10.18186/jte.76922.

[53] Yakhot V. and Orszag S.A. Renormalization group analysis of turbulence. I. Basic theory. Journal of scientific computing 1986;1(1);3-51. doi: 10.1007/BF01061452.

[54] Shirzad M., Ajarostaghi S.S.M., Delavar M.A. and Sedighi K. Improve the thermal performance of the pillow plate heat exchanger by using nanofluid: numerical simulation. Advanced Powder Technology 2019;30(7); 1356-1365. doi: 10.1016/j.apt.2019.04.011.

[55] Shirzad M., Delavar M.A., Ajarostaghi S.S.M. and Sedighi K. Evaluation the effects of geometrical parameters on the performance of pillow plate heat exchanger. Chemical Engineering Research and Design 2019;150;7483. doi: 10.1016/j.cherd.2019.06.032.

[56] Noorbakhsh M., Pourfallah M., Ajarostaghi S.S.M. and Zaboli M. Numerical evaluation and the effects of geometrical and operational parameters on thermal performance of the shell and double coil tube heat exchanger. Heat Transfer 2020. doi:10.1002/htj.21847.

[57] Ajarostaghi S.S.M., Shirzad M., Rashidi S. and Li L.K. Heat transfer performance of a nanofluid-filled tube with wall corrugations and center-cleared twisted-tape inserts. Energy Sources, Part A: Recovery, Utilization, and Environmental Effects 2020;1-21. doi: 10.1080/15567036.2020.1841860.

[58] Olfian H., Zabihi Sheshpoli A. and Ajarostaghi S.S.M. Numerical evaluation of the thermal performance of a solar air heater equipped with two different types of baffles. Heat Transfer 2020;49(3);1149-1169. doi: 10.1002/htj.21656.

[59] Hashemi Karouei S.H. and Ajarostaghi S.S.M. Influence of a curved conical turbulator on heat transfer augmentation in a helical double-pipe heat exchanger. Heat Transfer 2020. doi: 10.1002/htj.21960.

[60] Bergman, T.L., et al., Fundamentals of heat and mass transfer. 2011: John Wiley \& Sons.

[61] Eiamsa-Ard S., Thianpong C. and Eiamsa-Ard P. Turbulent heat transfer enhancement by counter/co-swirling flow in a tube fitted with twin twisted tapes. Experimental Thermal and Fluid Science 2010;34(1);53-62. doi: 10.1016/j.expthermflusci.2009.09.002. 